\title{
Influence of preoperative hemoglobin A1c on early outcomes in patients with diabetes mellitus undergoing off-pump coronary artery bypass surgery
}

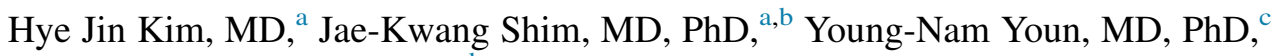
Jong-Wook Song, MD, PhD, ${ }^{\mathrm{a}, \mathrm{b}}$ Haeyeon Lee, MD, ${ }^{\mathrm{a}}$ and Young-Lan Kwak, MD, PhD ${ }^{\mathrm{a}, \mathrm{b}}$

\section{ABSTRACT}

Objective: There seem to be modifiable components of diabetes in terms of glycemic control to improve surgical outcome. The aim of the study was to evaluate impact of preoperative glycated hemoglobin $(\mathrm{HbAlc})$ level in patients with diabetes mellitus undergoing off-pump coronary bypass (OPCAB) on perioperative glycemic variability and short-term outcome.

Methods: Medical records of 703 patients with diabetes mellitus who underwent OPCAB from 2005 to 2017 were reviewed. The perioperative goal of glycemic control was $<180 \mathrm{mg} / \mathrm{dL}$. Patients were divided into 2 groups according to HbA1c level $(<7.0 \%$ or $\geq 7.0 \%)$. Glycemic variability during surgery and up to 24 hours after surgery was assessed by coefficient of variation (CV). Primary outcome was defined as composite of postoperative permanent stroke, prolonged ventilation, deep sternal wound infection, renal failure, reoperation, and 30-day mortality.

Results: Incidence of composite of postoperative morbidity and mortality endpoints was greater in patients with $\mathrm{HbA} 1 \mathrm{c} \geq 7.0 \%(21 \%$ vs $15 \%, P=.041)$. Perioperative time-weighted average glucose concentration was also greater in patients with $\mathrm{HbA} 1 \mathrm{c} \geq 7.0 \%$, whereas the $\mathrm{CV}$ did not show any difference. Multivariable logistic regression analysis revealed that congestive heart failure, chronic kidney disease, moderate mitral regurgitation or greater, preoperative hemoglobin level, and preoperative $\mathrm{HbA} 1 \mathrm{c} \geq 7.0 \%$ were independently associated with composite of postoperative morbidity and mortality, but perioperative $\mathrm{CV}$ and timeweighted average glucose $\geq 200 \mathrm{mg} / \mathrm{dL}$ were not.

Conclusions: Increased preoperative $\mathrm{HbA} 1 \mathrm{c}(\geq 7.0 \%)$ level reflecting long-term glycemic control seems to exert an adverse influence on outcome, whereas the influence of perioperative glycemic variables appear to be abrogated using a target glucose level of $<180 \mathrm{mg} / \mathrm{dL}$ in patients with diabetes mellitus undergoing OPCAB. (J Thorac Cardiovasc Surg 2020;159:568-76)

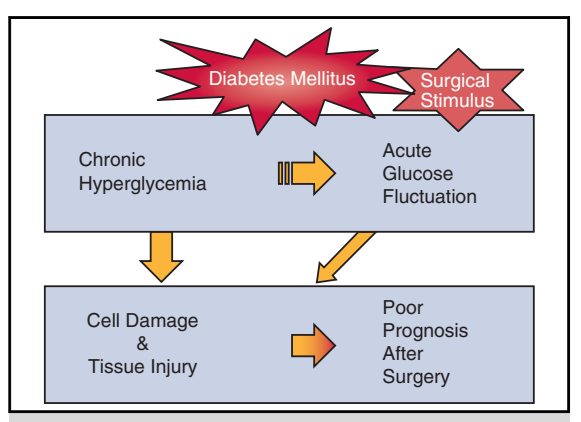

DM and chronic and acute glycemic control have a mutual effect on postoperative outcome.

\section{Central Message}

Preoperative $\mathrm{HbAlc}$ of $\geq 7 \%$ is a risk factor for increasing short-term postoperative composite morbidity/mortality in patients with diabetes undergoing off-pump coronary artery bypass.

\section{Perspective}

In patients with DM undergoing OPCAB, increased preoperative $\mathrm{HbAlc}(\geq 7.0 \%)$ level has potential influence on short-term postoperative adverse outcome, whereas perioperative glycemic variables including $\mathrm{CV}$ have low prognostic significance at target glucose level of $<180 \mathrm{mg} / \mathrm{dL}$. A prospective trial is required to determine whether postponing the surgery to lower $\mathrm{HbAlc}$ level would yield improved outcomes.

See Commentary on page 577.
From the ${ }^{\mathrm{a}}$ Department of Anesthesiology and Pain Medicine, ${ }^{\mathrm{b}}$ Anesthesia and Pain Research Institute, and ${ }^{\mathrm{c}}$ Department of Thoracic and Cardiovascular Surgery, Yonsei University College of Medicine, Seoul, Republic of Korea.

Received for publication July 30, 2018; revisions received Jan 23, 2019; accepted for publication Jan 23, 2019; available ahead of print March 2, 2019.

Address for reprints: Young-Lan Kwak, MD, PhD, Department of Anesthesiology and Pain Medicine, Yonsei University College of Medicine, 50-1 Yonsei-ro, Seodaemun-gu, Seoul, South Korea, 03722 (E-mail: ylkwak@yuhs.ac). $0022-5223 / \$ 36.00$

Copyright (c) 2019 by The American Association for Thoracic Surgery https://doi.org/10.1016/j.jtcvs.2019.01.086
Diabetes mellitus (DM) is a prevalent comorbidity among patients undergoing coronary artery bypass graft surgery (CABG) that is known to worsen outcome. ${ }^{1,2}$ Nonetheless, not all patients with DM undergoing cardiac surgery are at an increased risk of poor outcome. Several studies focused on influencing factors for increased risk, especially glycemic control, which has potential as a modifiable factor, have reported conflicting results. ${ }^{1,3,4}$ 

Abbreviations and Acronyms
$\mathrm{CABG}=$ coronary artery bypass graft surgery
CI = confidence interval
$\mathrm{CKD}=$ chronic kidney disease
$\mathrm{CMM}=$ composite of postoperative morbidity and mortality
$\mathrm{CPB}=$ cardiopulmonary bypass
$\mathrm{CV}=$ coefficient of variation
$\mathrm{DM}=$ diabetes mellitus
DSWI $=$ deep sternal wound infection
HbA1c $=$ glycated hemoglobin
ICU = intensive care unit
$\mathrm{OPCAB}=$ off-pump coronary artery bypass
$\mathrm{SD}=$ standard deviation
TWAG $=$ time-weighted average glucose

Glycated hemoglobin (HbA1c) level, a well-known index measure of long-term glycemic control of recent 3 to 4 months, has been reported to be related to microvascular dysfunction, inducing organ damage. ${ }^{5}$ The relationship between elevated HbAlc level and detrimental outcome has been investigated in various subsets of surgical patients. ${ }^{6-8}$ From the perspective of short-term glycemic control, perioperative hyperglycemia as well as increased glycemic variability were closely associated with adverse outcome in patients undergoing cardiac surgeries. $^{1-3}$

Perioperative glycemic control is affected by preoperative $\mathrm{HbA} 1 \mathrm{c}$ level and degree of surgical stress. ${ }^{7}$ Impact of $\mathrm{HbA1c}$ on perioperative glycemic control was influenced by severity of surgical stimulation such that at a greater level of stimulus, there was less effect of HbA1c on glycemic control. ${ }^{3}$ Thus, under cardiac surgery requiring cardiopulmonary bypass (CPB), a significant factor causing glucose dyshomeostasis, ${ }^{9}$ postoperative outcome might be less influenced by HbA1c level. ${ }^{10}$ In addition, DM was reported to alter the relationship between perioperative glycemic control and prognosis ${ }^{1,11}$ and weaken the influence of perioperative glycemic control on postoperative outcome. ${ }^{12}$

Off-pump coronary artery bypass surgery (OPCAB) without need for CPB results in less glucose dyshomeostasis than its on-pump counterpart ${ }^{9}$ and has been shown to be beneficial in certain groups of high-risk patients. ${ }^{13,14}$ Although DM has been recognized as a risk factor for adverse outcome in patients undergoing OPCAB, no comprehensive data have been reported on the distinguished impact of HbA1c level on perioperative glycemic control and prognosis. In this retrospective study, we aimed to investigate the effect of preoperative $\mathrm{HbA} 1 \mathrm{c}$ level on perioperative glycemic variability and short-term postoperative outcome in patients with DM undergoing OPCAB.

\section{METHODS}

Our institutional review board approved this study (no. 4-2018-0221), and the need for informed consent was waived. Data from electronic medical records were retrospectively collected from patients who underwent OPCAB from December 2005 to November 2017. Data of patients aged $\geq 20$ years with history of preoperative DM and available results of $\mathrm{HbA} 1 \mathrm{c}$ test within 3 months before surgery were included. Data of patients who had a history of previous CABG or whose surgery plan was changed to surgery through CPB were excluded.

Blood glucose levels were recorded before, during, and up to 24 hours after surgery in the intensive care unit (ICU). Intraoperative and postoperative glucose control and measurements were conducted under standard institutional guidelines. In the operating room, target blood glucose control in patients with $\mathrm{DM}$ was set to $<180 \mathrm{mg} / \mathrm{dL}^{15}$ and was measured using arterial blood gas test at 30-, 60-, or 120-minute intervals as necessary, and hyperglycemia was controlled by intermittent regular insulin (Humulin; Eli Lilly and Company, Indianapolis, Ind) injection. In the ICU, target blood glucose level was $<180 \mathrm{mg} / \mathrm{dL}$, and arterial blood glucose level was checked every 2 to 4 hours for the 12-hour postoperative period and every 4 to 8 hours thereafter; in cases with blood glucose level $>180 \mathrm{mg} / \mathrm{dL}$ for 2 consecutive measurements, insulin was injected per standard guideline (insulin protocol) of our institution. Per protocol, glucose concentration was checked at an interval of 2 hours until the target level was attained. The percent of hypoglycemia (blood glucose $<60 \mathrm{mg} / \mathrm{dL}$ ) and hyperglycemia (blood glucose $>200 \mathrm{mg} / \mathrm{dL}$ ) for each patient's readings that were examined was investigated. With regard to blood glycemic variability, standard deviation (SD) and coefficient of variation (CV) of blood glucose were evaluated during the perioperative period including intraoperative period and up to 24 hours postoperatively, and CV defined as the SD divided by the average was regarded as major variable. ${ }^{3}$ In addition, perioperative mean blood glucose concentration and time-weighted average glucose (TWAG) concentrations were calculated:

$\mathrm{TWAG}=\{[(\mathrm{X} 1+\mathrm{X} 2)(\mathrm{T} 2-\mathrm{T} 1)+(\mathrm{X} 2+\mathrm{X} 3)(\mathrm{T} 3-\mathrm{T} 2)+\cdots+$ $(\mathrm{Xn}-1+\mathrm{Xn})(\mathrm{Tn}-\mathrm{Tn}-1)] /[2 \times(\mathrm{Tn}-\mathrm{T} 1)]\}$

where $\mathrm{Tn}$ is nth time point and $\mathrm{Xn}$ is the blood sugar concentration at Tn.

TWAG is the average value between 2 consecutive measurements weighted by the time interval in which the measurement was made. Because intra- and postoperative TWAG $\geq 200 \mathrm{mg} / \mathrm{dL}$ were known to adversely affect the outcome, ${ }^{1}$ perioperative TWAG $\geq 200 \mathrm{mg} / \mathrm{dL}$ was also recorded for each patient.

Baseline patient demographic data were obtained including age, sex, presence of emergency operation, body surface area $\left(\mathrm{m}^{2}\right)$, euroSCORE, and history of hypertension, hyperlipidemia, cerebrovascular disease, congestive heart failure, unstable angina, myocardial infarction within 1 week before surgery, chronic kidney disease (CKD), chronic lung disease, peripheral arterial disease, and previous percutaneous coronary intervention. CKD was defined as estimated glomerular filtration rate $<60 \mathrm{~mL} /$ $\mathrm{min} / 1.73 \mathrm{~m}^{2}$ with the Chronic Kidney Disease Epidemiology Collaboration equation from serum creatinine. ${ }^{16}$ The Society of Thoracic Surgeons definitions were used for "cerebrovascular disease," "chronic lung disease," "peripheral arterial disease," and "prior percutaneous coronary intervention. ${ }^{17}$ Preoperative hemoglobin, creatinine, and albumin levels and estimated glomerular filtration rate calculated based on the Chronic Kidney Disease Epidemiology Collaboration equation from serum creatinine ${ }^{16}$ were evaluated. Moderate or higher mitral regurgitation grades on the preoperative echocardiography were recorded. Administered preoperative medications including aspirin, clopidogrel, beta blockers, calcium channel blockers, renin-angiotensin system antagonists, insulin, oral hypoglycemic agents, and $\beta$-hydroxy $\beta$-methylglutaryl-CoA reductase inhibitors were recorded. All oral hypoglycemic agents were discontinued at the morning of 
surgery, whereas other medications were all continued except clopidogrel, which was discontinued 3 to 5 days before surgery at the discretion of the attending physicians.

Assessment of intraoperative and postoperative data involved the number of grafts anastomosed, duration of operation, fluid and transfusion requirement, and urine output. During perioperative period, norepinephrine was used as first-line vasopressor, and vasopressin was administered in case of non-maintenance of target mean arterial pressure $(65-80 \mathrm{~mm} \mathrm{Hg})$ under increasing dose of norepinephrine (up to $0.3 \mu \mathrm{g} \cdot \mathrm{kg}^{-1} \cdot \mathrm{min}^{-1}$; first quartile). Intraoperatively, patients who had mixed venous oxygen saturation of $<60 \%$ for more than 10 minutes or new mitral regurgitation of grade $\geq 3$ and mean pulmonary arterial pressure $>30 \mathrm{~mm} \mathrm{Hg}$ received milrinone. In the ICU, in cases with cardiac index $>2.0 \mathrm{~L} \cdot \mathrm{min}^{-1} \cdot \mathrm{m}^{-2}$ or in whom mixed venous oxygen saturation $>60 \%$ could not be maintained despite adequate preload and hematocrit level, milrinone was used as primary inotrope. Chest tube drainage for 24 hours postoperatively, use of vasopressor and inotrope for 48 hours postoperatively, and perioperative use of insulin were recorded. Days of ICU and hospital stay after surgery and major complications and death after surgery were recorded.

The primary goal of the study was to investigate the effect of preoperative HbA1c level on the composite of postoperative morbidity and mortality (CMM) endpoints within 30 days after surgery. The secondary goals were to investigate the effect of preoperative $\mathrm{HbA} 1 \mathrm{c}$ level on perioperative glycemic variability and effect of short-term glycemic variability on CMM endpoints. Outcome variables were per definition of the Society of Thoracic Surgeons version 2.81 adult cardiac surgery database. ${ }^{17}$ These included permanent stroke (any confirmed neurologic deficit of abrupt onset caused by disturbance in blood supply to the brain), renal failure (serum creatinine level up to $\geq 4.0 \mathrm{mg} / \mathrm{dL}$ with increase of $\geq 0.5 \mathrm{mg} / \mathrm{dL}$ or $3 \times$ most recent preoperative creatinine level; new requirement for dialysis postoperatively), prolonged ventilation ( $>24$ hours), deep sternal wound infection (DSWI), and reoperation. The definition of operative mortality was all deaths, regardless of cause, that occurred during hospitalization in which operation was performed or before the end of postoperative day 30 .

\section{Statistical Analysis}

In this study, enrolled patients were divided into 2 groups according to HbA1c level $(<7.0 \%$ or $\geq 7.0 \%)$. HbA1c $7.0 \%$ is the reference point for predicting the occurrence of complications and mortality in studies including patients with DM. ${ }^{6,18}$ The American Diabetes Association recommends maintaining target $\mathrm{HbA} 1 \mathrm{c}<7.0 \%$ in nonpregnant adults with DM. ${ }^{19}$ Postoperative complications, mortality, and perioperative glycemic variability were compared between patients with $\mathrm{HbA} 1 \mathrm{c} \geq 7.0 \%$ and $<7.0 \%$. Continuous variables were analyzed by independent $t$ test or Mann-Whitney $U$ test according to results from Shapiro-Wilk test for normality. Categorical variables were analyzed by the $\chi^{2}$ test or Fisher exact test. All analyses were performed through Statistical Package for the Social Sciences (SPSS) version 23 software (IBM Corp, Armonk, NY), R version 3.4.1 (The R Foundation for Statistical Computing, Vienna, Austria), and SAS (version 9.4; SAS Inc, Cary, NC).

"Age," "sex," and variables of interest "HbA1c $\geq 7.0$," "perioperative CV" (as our main glycemic variables), "TWAG $\geq 200 \mathrm{mg} / \mathrm{dL}$," and clinically significant factors among preoperative characteristics that might affect postoperative outcome were entered into a multivariable logistic model for assessment of their impact on CMM. For satisfying the rule of 10, the variables with a $P$ value of less than .05 in the univariable analysis were included preferentially. After that, the remaining variables that increase the predictive power of the model were also included within the range of the rule of 10 . Statistical significance was set as $P<.05$.

\section{RESULTS}

Overall, 703 patients were included (Figure 1), and there were no missing data for validating our hypothesis.
Preoperative $\mathrm{HbAlc}$ was $<7 \%$ in 287 patients $(41 \%$, normal HbAlc group) and $\geq 7.0 \%$ in 416 patients $(59 \%$, high $\mathrm{HbAlc}$ group). Patients in the high $\mathrm{HbAlc}$ group were younger, with greater preoperative serum glucose levels $(151$ [114-211] $\mathrm{mg} / \mathrm{dL}$ vs 128 [104-153] mg/dL, $P<.001)$ and more frequent history of preoperative insulin use $(16 \%$ vs $6 \%, P<.001)$ (Table 1$)$. Remaining characteristics including comorbidities were similar between the groups.

In all patients, during perioperative period, arterial glucose measurements were conducted at least 6 times. Perioperative mean serum glucose concentration (183 [167-202] mg/dL vs 160 [147-178] mg/dL, $P<.001)$, SD of glucose $(37$ [27-51] $\mathrm{mg} / \mathrm{dL}$ vs 32 [23-41] $\mathrm{mg} / \mathrm{dL}$, $P<.001)$, and patients with TWAG $\geq 200 \mathrm{mg} / \mathrm{dL}(11 \%$ vs $35 \%, P<.001)$ were significantly greater in the high HbA1c group than in the normal HbA1c group, whereas the CV showed no significant intergroup difference. Frequency of insulin use $(89 \%$ vs $69 \%, P<.001)$ and hyperglycemic event $(33.3 \%$ vs $11.1 \%, P<.001)$ were significantly greater in the high $\mathrm{HbA1c}$ group than in the normal HbA1c group (Table 2).

Operative data showed no statistically significant differences between the 2 groups (Table 3). Amount of postoperative bleeding (770 [580-981] mL vs 710 [541-890] mL, $P=.012)$ and transfusion requirement of packed erythrocytes $(37 \%$ vs $29 \%, P=.029)$ were significantly greater in the normal HbA1c group than in the high HbAlc group (Table 3).

Incidence of CMM endpoints was significantly greater in the high $\mathrm{HbAlc}$ group than in the normal $\mathrm{HbA1c}$ group $(21 \%$ vs $15 \%, P=.041)$. DSWI was significantly more frequent ( $6 \%$ vs $2 \%, P=.019)$, whereas the high $\mathrm{HbA1c}$ group had a clinically meaningful greater incidence of renal failure, but this result did not reach statistical significance ( $5 \%$ vs $2 \%, P=.062)$ in the high HbA1c group than in the normal HbA1c group (Table 4). Mortality was not significantly different between the 2 groups.

In univariable analysis, congestive heart failure, CKD, previous percutaneous coronary intervention, moderate mitral regurgitation or greater, preoperative hemoglobin level, and preoperative $\mathrm{HbA} 1 \mathrm{c} \geq 7.0 \%$ were positively associated with increased CMM endpoints. Perioperative glycemic variables were not significantly associated with CMM. In multivariable logistic regression analysis, congestive heart failure, CKD, moderate mitral regurgitation or greater, preoperative hemoglobin level, and preoperative $\mathrm{HbA} 1 \mathrm{c} \geq 7.0 \%$ were independently associated with the CMM endpoints, but perioperative $\mathrm{CV}$ and TWAG $\geq 200 \mathrm{mg} / \mathrm{dL}$ were not (Table 5). When introducing the $\mathrm{HbA1c}$ as a continuous variable (excluding categorical $\mathrm{HbA1c}$ variable) to the multivariable model, it was not identified as an independent risk factor for adverse outcome (odds ratio, 1.126, 95\% confidence interval [CI], 0.987- 


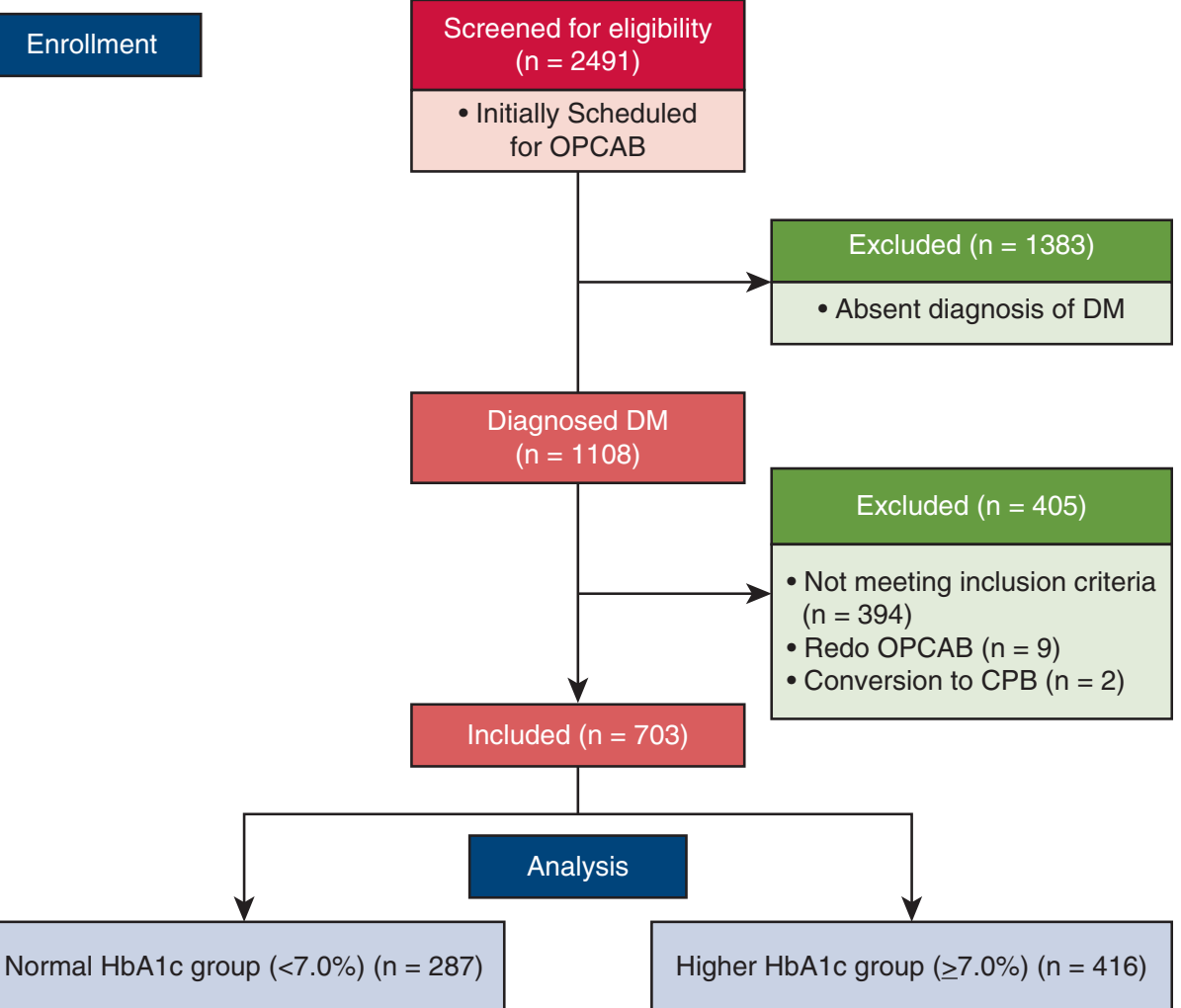

FIGURE 1. Flowchart of the patients' enrollment. Among the 2491 patients who underwent off-pump coronary artery bypass surgery from December 2005 to November 2017 in the institution, 1108 (44.5\%) patients were diagnosed with diabetes mellitus before surgery. Of the 1108 patients with diabetes mellitus, 394 did not meet the inclusion criteria. Among the remaining 714 patients, 9 patients who received redo off-pump coronary artery bypass surgery and 2 patients who were converted to an emergent on-pump surgery were excluded. Finally, 703 patients were divided into 2 groups based on a preoperative HbA1c level of $7.0 \%$. OPCAB, Off-pump coronary artery bypass; $D M$, diabetes mellitus; $C P B$, cardiopulmonary bypass; HbAlc, glycated hemoglobin.

$1.285, P=.078$ ), whereas the significance of other variables did not change. Receiver operator-characteristic curve analysis revealed HbA1c $7.85 \%$ as the optimal threshold for CMM endpoints (area under the curve; 0.556, 95\% CI, $0.501-0.611, P=.048$ ) and DSWI (area under the curve: $0.661 ; 95 \% \mathrm{CI}, 0.565-0.757, P=.002)$.

The mortality $(\beta:-0.038, P=.528)$ and morbidity $(\beta$ : $0.428, P=.228$ ) rates did not vary over the study period (12 years). Thus, dividing the time frame was not considered.

\section{DISCUSSION}

In the current study, preoperative $\mathrm{HbAlc}$ of $\geq 7 \%$ was determined as an independent risk factor for short-term adverse outcome in patients with DM undergoing OPCAB. Preoperative $\mathrm{HbAlc}$ of $\geq 7 \%$ adversely affected perioperative glycemic variables, including the $\mathrm{SD}$, mean, and TWAG, but not the CV of glucose. None of the glycemic variables except $\mathrm{HbA} 1 \mathrm{c} \geq 7 \%$ was associated with unfavorable prognosis.

$\mathrm{DM},{ }^{3} \mathrm{HbAlc},{ }^{6,8}$ and perioperative glycemic control ${ }^{1,20}$ are closely interlinked variables, either independent or interrelated, that have been shown to exert adverse influence on outcome after cardiac surgery through the following underlying mechanisms (Figure 2). DM is known to worsen endothelial function and increase oxidative stress and inflammation; chronic hyperglycemia, reflected by increased $\mathrm{HbA} 1 \mathrm{C}$ level, has been shown to further aggravate cell damage. ${ }^{21} \mathrm{~A}$ representative study investigating the role of $\mathrm{HbA} 1 \mathrm{c}$ in outcome after cardiac surgery showed that hospital mortality, cerebrovascular accident, renal failure, and DSWI were significantly increased in patients with $\mathrm{HbAlc} \geq 7 \%$, regardless of the presence of DM. ${ }^{6}$ Interestingly, the prognostic role of increased $\mathrm{HbA} 1 \mathrm{c}$ was limited to fewer complications in patients with DM. In another study including patients with and without DM undergoing CABG, $\mathrm{HbAlc}$ was identified as an independent risk factor for respiratory complication and sternal wound infection in patients with DM, whereas its adverse influence disappeared in patients without DM. ${ }^{22}$

These controversies are also present in studies focusing on perioperative glycemic control. Perioperative hyperglycemia is known to reduce leucocyte activity, activate coagulation, and delay recovery. ${ }^{23}$ In addition, acute glucose fluctuation causes oxidative stress $^{24}$ and endothelial dysfunction. ${ }^{25}$ Indeed, with regard to increased glycemic variability, both 
TABLE 1. Preoperative characteristics of patients

\begin{tabular}{|c|c|c|c|}
\hline Variable & HbA1c $<7 \% \mathbf{n}=\mathbf{2 8 7}$ & HbA1c $\geq 7 \% n=416$ & $P$ value \\
\hline \multicolumn{4}{|l|}{ Patient } \\
\hline Age, $y$ & $67 \pm 8$ & $65 \pm 8$ & .014 \\
\hline Female sex & $79(28 \%)$ & $125(30 \%)$ & .469 \\
\hline Emergency & $2(1 \%)$ & $8(2 \%)$ & .212 \\
\hline Body surface area, $\mathrm{m}^{2}$ & $1.70 \pm 0.16$ & $1.72 \pm 0.38$ & .561 \\
\hline Hypertension & $235(82 \%)$ & $326(78 \%)$ & .254 \\
\hline Cerebrovascular accident & $51(18 \%)$ & $58(14 \%)$ & .168 \\
\hline Congestive heart failure & $51(18 \%)$ & $62(15 \%)$ & .309 \\
\hline Chronic kidney disease & $36(13 \%)$ & $57(14 \%)$ & .656 \\
\hline Chronic lung disease & $21(7 \%)$ & $22(5 \%)$ & .270 \\
\hline Peripheral arterial disease & $21(7 \%)$ & $45(11 \%)$ & .118 \\
\hline Previous percutaneous coronary intervention & $85(30 \%)$ & $110(26 \%)$ & .355 \\
\hline Moderate mitral regurgitation or greater & $7(2.4 \%)$ & $15(3.6 \%)$ & .384 \\
\hline Unstable angina & $105(37 \%)$ & $142(34 \%)$ & .503 \\
\hline Myocardial infarction within $1 \mathrm{wk}$ & $22(8 \%)$ & $48(12 \%)$ & .092 \\
\hline Left main $>50 \%$ stenosis & $87(31 \%)$ & $105(26 \%)$ & .224 \\
\hline Triple coronary artery disease & $247(86 \%)$ & $375(90 \%)$ & .096 \\
\hline \multicolumn{4}{|l|}{ Preoperative medications } \\
\hline Aspirin & $236(82 \%)$ & $348(84 \%)$ & .621 \\
\hline Clopidogrel & $186(65 \%)$ & $247(59 \%)$ & .145 \\
\hline Beta blocker & $168(59 \%)$ & $250(60 \%)$ & .679 \\
\hline Calcium channel blocker & $144(50 \%)$ & $180(43 \%)$ & .071 \\
\hline RAS inhibitor & $174(61 \%)$ & $245(59 \%)$ & .645 \\
\hline Statins & $211(74 \%)$ & $305(73 \%)$ & .953 \\
\hline Oral hypoglycemic agents & $253(88 \%)$ & $361(87 \%)$ & .590 \\
\hline Insulin & $16(6 \%)$ & $68(16 \%)$ & $<.001$ \\
\hline euroSCORE & $4[3-6]$ & $4[3-6]$ & .654 \\
\hline \multicolumn{4}{|l|}{ Laboratory data } \\
\hline Serum glucose level, $\mathrm{mg} / \mathrm{dL}$ & $128[104-153]$ & $151[114-211]$ & $<.001$ \\
\hline Hemoglobin level, g/dL & $12.6 \pm 1.8$ & $12.6 \pm 1.9$ & .993 \\
\hline Serum albumin level, $g / d L$ & $4.1[3.8-4.4]$ & $4.1[3.7-4.4]$ & .076 \\
\hline
\end{tabular}

Values are mean \pm standard deviation, median [first quartile-third quartile], or the number of patients (percent). HbAlc, Glycated hemoglobin; $R A S$, renin-angiotensin system; euroSCORE, European System for Cardiac Operative Risk Evaluation.

the CV and hyperglycemia ( $>200 \mathrm{mg} / \mathrm{dL}$ ) have been reported to be predictors of poor prognosis in patients undergoing cardiac surgery ${ }^{1}$; however, intraoperative glycemic control to near normoglycemic level was not associated with reduced risk in the same study. In some cases, the presence of DM may regulate negative influence of poor perioperative glycemic control on outcome, with consequent less net influence. In critically ill patients, interaction between hyperglycemia and/or glycemic variability and mortality was reported to be much stronger in patients without DM. ${ }^{26,27}$ The optimal

TABLE 2. Glycemic variables during operation and 24 hours postoperatively

\begin{tabular}{lcccc}
\hline \multicolumn{1}{c}{ Variable } & HbA1c $<\mathbf{7 \%} \mathbf{n}=\mathbf{2 8 7}$ & HbA1c $\geq \mathbf{7 \%} \mathbf{n}=\mathbf{4 1 6}$ & $\boldsymbol{P}$ value \\
\hline Mean glucose, $\mathrm{mg} / \mathrm{dL}$ & $160[47-178]$ & $183[167-202]$ & $185[164-208]$ & $<.001$ \\
TWAG, $\mathrm{mg} / \mathrm{dL}$ & $164[145-182]$ & $144(35 \%)$ & $<.001$ \\
TWAG $>$ 200, $\mathrm{mg} / \mathrm{dL}$ & $31(11 \%)$ & $37[27-51]$ & $<.001$ \\
SD of glucose, $\mathrm{mg} / \mathrm{dL}$ & $32[23-41]$ & $20.8[15.1-28.1]$ & $<.001$ \\
CV of glucose, $\%$ & $20.0[14.6-25.3]$ & $372(89 \%)$ & .094 \\
Perioperative use of insulin & $198(69 \%)$ & $33.3[12.5-50.0]$ & $<.001$ \\
Hyperglycemic event, \% & $11.1[0.0-25.0]$ & $0.0[0.0-0.0]$ & .001 \\
\hline Hyporglycemic event, $\%$ & $0.0[0.0-0.0]$ & .691 \\
\hline
\end{tabular}

Values are median [first quartile-third quartile] or the number of patients (percent). HbAlc, Glycated hemoglobin; $T W A G$, time-weighted average glucose; $S D$, standard deviation; $\mathrm{CV}$, coefficient of variation. 
TABLE 3. Intraoperative and postoperative data

\begin{tabular}{|c|c|c|c|}
\hline Variable & HbA1c $<7 \% n=287$ & HbA1c $\geq 7 \% n=416$ & $P$ value \\
\hline \multicolumn{4}{|l|}{ Intraoperative } \\
\hline Graft number & $3[3-4]$ & $3[3-4]$ & .262 \\
\hline Duration of anesthesia, min & $300[275-330]$ & $300[275-330]$ & .717 \\
\hline Crystalloids, $\mathrm{mL}$ & $1900[1350-2500]$ & $1800[1350-2500]$ & .872 \\
\hline Colloids, $\mathrm{mL}$ & $500[500-1000]$ & $500[500-1000]$ & .227 \\
\hline Urine output, $\mathrm{mL}$ & $380[220-630]$ & 365 [210-603] & .497 \\
\hline Number of patients transfused & $101(35 \%)$ & $139(33 \%)$ & .625 \\
\hline Salvaged blood, $\mathrm{mL}$ & $200[120-250]$ & $173[120-240]$ & .066 \\
\hline \multicolumn{4}{|l|}{ Postoperative } \\
\hline Crystalloid for $24 \mathrm{~h}, \mathrm{~mL}$ & 3298 [2866-3945] & $3461[3033-3865]$ & .228 \\
\hline Colloid for $24 \mathrm{~h}, \mathrm{~mL}$ & $250[0-500]$ & $235[0-500]$ & .304 \\
\hline Urine output for $24 \mathrm{~h}, \mathrm{~mL}$ & 2955 [2425-3420] & $2930[2370-3460]$ & .557 \\
\hline Bleeding for $24 \mathrm{~h}$ & $770[580-981]$ & $710[541-890]$ & .012 \\
\hline Patients transfused with $\mathrm{RBC}$ & $106(37 \%)$ & $121(29 \%)$ & .029 \\
\hline Vasopressor use for $48 \mathrm{~h}$ & $208(73 \%)$ & $283(68 \%)$ & .207 \\
\hline Inotrope use for $48 \mathrm{~h}$ & $45(16 \%)$ & $68(16 \%)$ & .813 \\
\hline
\end{tabular}

Values are median [first quartile-third quartile] or the number of patients (percent). HbAlc, Glycated hemoglobin; RBC, red blood cell.

target of glycemic control in patients with DM, especially those with high HbA1c levels, is not clear, as due to cellular adaptation to the high-glucose milieu, mild-tomoderate hyperglycemia may be beneficial to these patients. $^{28,29}$ In addition to the complex interrelationship among DM, HbAlc, and perioperative glycemic control, inconsistencies regarding their influence on outcome after cardiac surgery may be attributed to the use of CPB. CPB inevitably provokes glucose dyshomeostasis, which is expected to significantly alter the interrelationship among $\mathrm{DM}$ and glycemic variables, as well as their prognostic value.

OPCAB is an important technique of surgical revascularization, which has been shown to be beneficial compared with on-pump CABG in certain high-risk patient groups, such as those with advanced age or acute coronary syndrome. $^{13,14}$ By eliminating the requirement of CPB, perioperative glucose homeostasis is significantly less altered as compared to that with on-pump CABG. ${ }^{9}$ Although interaction among DM, $\mathrm{HbA} 1 \mathrm{c}$, and perioperative glycemic control as well as their prognostic role are expected to differ in patients undergoing OPCAB, supportive evidence is limited. Certainly, not all patients with DM share the same risk of adverse outcome, and analysis of the impact of DM-related variables as potential modifiable risk factors is of clinical significance.

Our data indicated that high HbA1c $(\geq 7.0 \%)$ level alone, and not the variables related to perioperative glycemic control, was independently associated with adverse outcome in patients with DM undergoing $\mathrm{OPCAB}$, although high $\mathrm{HbA1c}$ levels contributed to greater perioperative glycemic variability. The high $\mathrm{HbA} 1 \mathrm{c}$ group showed an increased risk of poor prognosis despite presence of younger age, lower level of blood loss, and less transfusion requirement compared with the normal HbA1c group. Insulin, which itself exerts a beneficial effect on inflammation and metabolism, ${ }^{30}$ was more frequently administered in the high $\mathrm{HbA1c}$ group than in the normal HbA1c group. Nevertheless, adverse outcome was more prevalent in the high

TABLE 4. Comparison of postoperative outcomes

\begin{tabular}{lccc}
\hline \multicolumn{1}{c}{ Variable } & HbA1c $<\mathbf{7 \%} \mathbf{n}=\mathbf{2 8 7}$ & HbA1c $\geq \mathbf{7 \%} \mathbf{n}=\mathbf{4 1 6}$ & $\boldsymbol{P}$ value \\
\hline Composite morbidity/mortality & $42(15 \%)$ & $86(21 \%)$ & .041 \\
Renal failure & $7(2 \%)$ & $22(5 \%)$ & .062 \\
Permanent stroke & $2(1 \%)$ & $6(1 \%)$ & .483 \\
Hemostatic reoperation & $5(2 \%)$ & $5(1 \%)$ & .748 \\
Deep stenal infection & $7(2 \%)$ & $26(6 \%)$ & .019 \\
Prolonged ventilation & $28(10 \%)$ & $41(10 \%)$ & .965 \\
Mortality & $5(2 \%)$ & $5(1 \%)$ & .748 \\
Duration of intensive care unit stay, d & $2[2-3]$ & $2[2-3]$ & .645 \\
Duration of hospitalization, d & $9[7-11]$ & $9[8-12]$ & .163 \\
\hline
\end{tabular}

Values are median [first quartile-third quartile], or the number of patients (percent). HbAlc, Glycated hemoglobin. 
TABLE 5. Risk factors for the composite of morbidity and mortality end points

\begin{tabular}{|c|c|c|}
\hline Variable & $\frac{\text { Multivariable }}{\text { OR (CI) }}$ & $P$ value \\
\hline Age, y & $1.01(0.98-1.03)$ & .740 \\
\hline Female sex & $1.07(0.67-1.71)$ & .767 \\
\hline Congestive heart failure & $1.64(1.00-2.70)$ & .050 \\
\hline Chronic kidney disease & $2.00(1.16-3.46)$ & .013 \\
\hline Peripheral arterial disease & $1.24(0.65-2.37)$ & .513 \\
\hline $\begin{array}{l}\text { Previous percutaneous coronary } \\
\text { intervention }\end{array}$ & $1.52(0.99-2.34)$ & .059 \\
\hline Moderate mitral regurgitation or greater & $4.47(1.77-11.30)$ & .002 \\
\hline Preoperative hemoglobin, g/dL & $0.80(0.70-0.91)$ & .001 \\
\hline Hemoglobin A1c $\geq 7 \%$ & $1.60(1.03-2.50)$ & .038 \\
\hline Perioperative $\mathrm{CV}$ of glucose, $\%$ & $0.98(0.96-1.01)$ & .133 \\
\hline Perioperative TWAG $\geq 200 \mathrm{mg} / \mathrm{dL}$ & $1.05(0.64-1.71)$ & .848 \\
\hline
\end{tabular}

HbA1c group, supporting the important role of increased $\mathrm{HbA1c}$ as a prognostic marker in patients with DM undergoing OPCAB.

These findings contrast with the results of the only 2 previous studies performed in patients with DM undergoing OPCAB that reported no relationship between $\mathrm{HbA} 1 \mathrm{c}$ level and postoperative outcome. ${ }^{31,32}$ Moreover, another study including patient groups with and without DM reported that occurrence of atrial fibrillation after CABG was significantly less frequent in patients with greater $\mathrm{HbA} 1 \mathrm{c}$ levels. ${ }^{33}$ These inconsistencies might be due to the following: Both previous studies on patients with DM undergoing OPCAB included small sample sizes (306 and 101 patients, respectively), which could result in a type II statistical error, and cut-off values of $\mathrm{HbA} 1 \mathrm{c}$ ranging from $6.5 \%$ to $7.5 \%$, as compared with that of $7.0 \%$ for poor preoperative long-term glycemic control in the present study. In our study, selection of the cut-off value was based on its prognostic importance in patients undergoing cardiac surgery ${ }^{6,18}$ and the guideline of the American Diabetes Association. ${ }^{19}$ Both previous studies did not clarify predefined glycemic control guidelines and perioperative glycemic variables, whereas in the current study, perioperative glycemic control was done per protocol, ${ }^{15}$ and perioperative glycemic control data consisted of at least 6 repeated glucose measurements per patient. Thus, the strength of our study lies in that it is the first of its kind to concomitantly address the influence of preoperative long-term glycemic control (HbA1c) and acute perioperative glycemic control (CV and TWAG) on outcome in a fairly large number of patients with DM undergoing OPCAB using a comprehensive data set of glycemic variables.

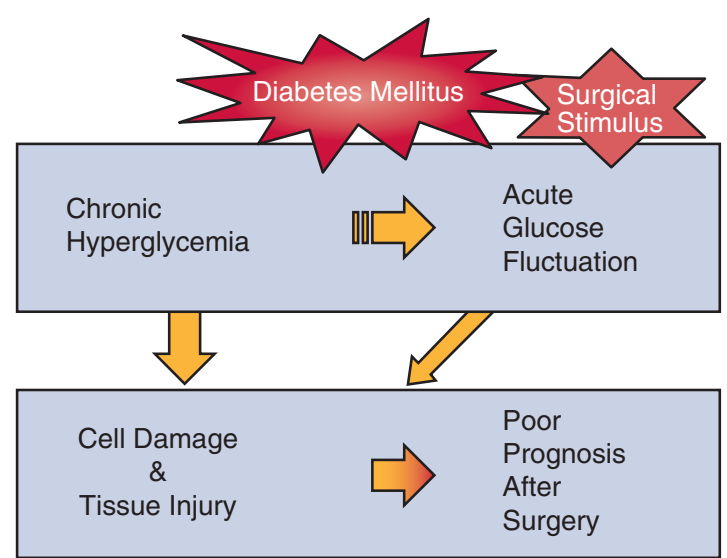

FIGURE 2. Diabetes mellitus and chronic and acute glycemic control are closely interlinked and exert adverse influence on patient's outcome after cardiac surgery, either independently or interrelatedly. In addition to the complex interrelationship among diabetes mellitus, preoperative chronic hyperglycemia, and perioperative acute glucose fluctuation, inconsistencies regarding their influence on outcome after cardiac surgery may occur depending on the strength of the surgical stimulus.

In our study, all perioperative glycemic variables except the $\mathrm{CV}$ were significantly greater in the high $\mathrm{HbAlc}$ group. The rate of perioperative hyperglycemic event and use of insulin were significantly more frequent in the high $\mathrm{HbAlc}$ group, whereas the incidence of hypoglycemia was similar in both groups. In patients with elevated HbAlc levels, lower vulnerability to hyperglycemia through adaptive response to chronic hyperglycemia could have contributed to the observed lack of impact of perioperative glycemic control on poor prognosis. ${ }^{12}$ Nonetheless, mean glucose values, including TWAG, were only slightly above the target value $(<180 \mathrm{mg} / \mathrm{dL})$, even in the high HbA1c group, with a mere mean intergroup difference of $21 \mathrm{mg} / \mathrm{dL}$. Moreover, CV of glucose was less than previously reported values in patients undergoing on-pump $\mathrm{CABG},{ }^{3}$ without any intergroup difference due to a slightly greater SD of glucose concentration in the high HbA1c group. In studies reporting adverse relationship between glycemic control and shortterm outcome, ${ }^{1,2}$ TWAG or CV was greater, indicating large fluctuations in glycemic control under CPB. Thus, our findings clearly indicate the importance of preoperative long-term glycemic control on outcome over the perioperative glycemic control in patients with DM undergoing $\mathrm{OPCAB}$ under standardized glycemic control protocol $(<180 \mathrm{mg} / \mathrm{dL})$ without considerable swings in glycemic control.

With regard to evaluated morbidity endpoints, DSWI showed significantly lower frequency of occurrence, and renal failure showed a trend of lower incidence in the normal $\mathrm{HbA1c}$ group. Patients with infection and acute kidney injury were reported to be more vulnerable to chronic hyperglycemia due to reduced humoral and cell immunity 
and defense action mechanism, ${ }^{34}$ as well as increased apoptosis and caspase activity, which collectively enhances tissue injury. ${ }^{35}$

The limitations of the present study are as follows. The study had a retrospective design with an inherent limitation with respect to validating causality. Furthermore, dichotomization of a continuous variable (HbA1c) that may show a nonlinear relationship with outcome for ease of clinical applicability results in reduced statistical power and incomplete correction for confounders. More intriguingly, $\mathrm{HbA} 1 \mathrm{c}$ as a continuous variable only showed a statistical trend toward being an independent risk factor of adverse outcome, possibly indicating a reduced statistical power as well. Similarly, receiver operator-characteristic curve analysis revealed $\mathrm{HbA} 1 \mathrm{c} 7.85 \%$ as the optimal threshold for CMM (area under the curve: $0.556, P=.048$ ) and DSWI (area under the curve: $0.661, P=.002$ ), showing small areas under the curve despite being statistically significant. Yet, our analyses are intended as hypothesis-generating results for future prospective studies with sufficient power to appropriately examine whether postponing the surgery to lower $\mathrm{HbA1c}$ level would actually yield improved outcome.

In conclusion, the current study provides novel evidence that increased preoperative HbAlc $(\geq 7.0 \%)$ levels showed potential as an important influencing factor on patients' adverse outcome, whereas at a target glucose level of $<180 \mathrm{mg} / \mathrm{dL}$, perioperative glycemic variables were not associated with poor prognosis in patients with DM undergoing OPCAB.

\section{Conflict of Interest Statement}

Authors have nothing to disclose with regard to commercial support.

We thank Dr Yoo and Dr Youn for performing the surgeries. We thank Dr Youn, Severance Cardiovascular Hospital, Yonsei University, College of Medicine, for his guidance during the course of research. We thank Professor Jinae Lee, Biostatistics Collaboration Unit, Yonsei University, College of Medicine, for giving advice and practical help in statistical analysis.

\section{References}

1. Duncan AE, Abd-Elsayed A, Maheshwari A, Xu M, Soltesz E, Koch CG. Role of intraoperative and postoperative blood glucose concentrations in predicting outcomes after cardiac surgery. Anesthesiology. 2010;112:860-71.

2. Ouattara A, Lecomte P, Le Manach Y, Landi M, Jacqueminet S, Platonov I, et al. Poor intraoperative blood glucose control is associated with a worsened hospital outcome after cardiac surgery in diabetic patients. Anesthesiology. 2005;103:687-94.

3. Masla M, Gottschalk A, Durieux ME, Groves DS. HbA1c and diabetes predict perioperative hyperglycemia and glycemic variability in on-pump coronary artery bypass graft patients. J Cardiothorac Vasc Anesth. 2011;25:799-803.

4. Wang TKM, Woodhead A, Ramanathan T, Pemberton J. Relationship between diabetic variables and outcomes after coronary artery bypass grafting in diabetic patients. Heart Lung Circ. 2017;26:371-5.

5. Stratton IM, Adler AI, Neil HA, Matthews DR, Manley SE, Cull CA, et al. Association of glycaemia with macrovascular and microvascular complications of type 2 diabetes (UKPDS 35): prospective observational study. BMJ. 2000;321: 405-12.
6. Halkos ME, Puskas JD, Lattouf OM, Kilgo P, Kerendi F, Song HK, et al. Elevated preoperative hemoglobin Alc level is predictive of adverse events after coronary artery bypass surgery. J Thorac Cardiovasc Surg. 2008;136:631-40.

7. Gustafsson UO, Thorell A, Soop M, Ljungqvist O, Nygren J. Haemoglobin A1c as a predictor of postoperative hyperglycaemia and complications after major colorectal surgery. Br J Surg. 2009;96:1358-64.

8. Goodenough CJ, Liang MK, Nguyen MT, Nguyen DH, Holihan JL, Alawadi ZM, et al. Preoperative glycosylated hemoglobin and postoperative glucose together predict major complications after abdominal surgery. J Am Coll Surg. 2015; 221:854-61.e851.

9. Anderson RE, Brismar K, Barr G, Ivert T. Effects of cardiopulmonary bypass on glucose homeostasis after coronary artery bypass surgery. Eur J Cardiothorac Surg. 2005;28:425-30.

10. Göksedef D, ÖS, Yalvaç E, Bitargil M, İpek G. Is elevated HbA1c a risk factor for infection after coronary artery bypass grafting surgery. Turkish J Thorac Cardiovasc Surg. 2010;18:252-8.

11. Greco G, Kirkwood KA, Gelijns AC, Moskowitz AJ, Lam DW. Diabetes is associated with reduced stress hyperlactatemia in cardiac surgery. Diabetes Care. 2018;41:469-77.

12. Kotagal M, Symons RG, Hirsch IB, Umpierrez GE, Dellinger EP, Farrokhi ET, et al. Perioperative hyperglycemia and risk of adverse events among patients with and without diabetes. Ann Surg. 2015;261:97-103.

13. Puskas JD, Thourani VH, Kilgo P, Cooper W, Vassiliades T, Vega JD, et al. Offpump coronary artery bypass disproportionately benefits high-risk patients. Ann Thorac Surg. 2009;88:1142-7.

14. Rastan AJ, Eckenstein JI, Hentschel B, Funkat AK, Gummert JF, Doll N, et al Emergency coronary artery bypass graft surgery for acute coronary syndrome: beating heart versus conventional cardioplegic cardiac arrest strategies. Circulation. 2006;114:I477-85.

15. Lazar HL, McDonnell M, Chipkin SR, Furnary AP, Engelman RM, Sadhu AR, et al. The Society of Thoracic Surgeons practice guideline series: blood glucose management during adult cardiac surgery. Ann Thorac Surg. 2009;87:663-9.

16. Levey AS, Stevens LA, Schmid CH, Zhang YL, Castro AF 3rd, Feldman HI, et al. A new equation to estimate glomerular filtration rate. Ann Intern Med. 2009;150: 604-12.

17. STS Adult Cardiac Surgery Database Data Specifications Version 2.81. Available at: https://www.sts.org/sites/default/files/documents/ACSD_DataSpecificationsV2_ 81.pdf. Accessed March 5, 2018.

18. Ramadan M, Abdelgawad A, Elshemy A, Sarawy E, Emad A, Mazen M, et al Impact of elevated glycosylated hemoglobin on hospital outcome and 1 year survival of primary isolated coronary artery bypass grafting patients. Egypt Heart J. 2018;70:113-8.

19. 6. Glycemic Targets: Standards of Medical Care in Diabetes-2018. Diabetes Care. 2018;41:S55-64.

20. Subramaniam B, Lerner A, Novack V, Khabbaz K, Paryente-Wiesmann M Hess $\mathrm{P}$, et al. Increased glycemic variability in patients with elevated preoperative $\mathrm{HbA1C}$ predicts adverse outcomes following coronary artery bypass grafting surgery. Anesth Analg. 2014;118:277-87.

21. Manigrasso MB, Juranek J, Ramasamy R, Schmidt AM. Unlocking the biology of RAGE in diabetic microvascular complications. Trends Endocrinol Metab. 2014;25:15-22.

22. Narayan P, Naresh Kshirsagar S, Mandal C, Auddya Ghorai P, Manjunatha Rao Y, Das D, et al. Preoperative glycosylated hemoglobin: a risk factor for patients undergoing coronary artery bypass. Ann Thorac Surg. 2017; 104:606-12.

23. Polderman JAW, Hollmann MW, DeVries JH, Preckel B, Hermanides J. Perioperative hyperglycemia and glucose variability in gynecologic laparotomies. $J$ Diabetes Sci Technol. 2016;10:145-50.

24. Monnier L, Mas E, Ginet C, Michel F, Villon L, Cristol JP, et al. Activation of oxidative stress by acute glucose fluctuations compared with sustained chronic hyperglycemia in patients with type 2 diabetes. J Am Med Assoc. 2006;295: 1681-7.

25. Ceriello A, Esposito K, Piconi L, Ihnat MA, Thorpe JE, Testa R, et al. Oscillating glucose is more deleterious to endothelial function and oxidative stress than mean glucose in normal and type 2 diabetic patients. Diabetes. 2008;57:1349.

26. Krinsley JS. Glycemic variability and mortality in critically ill patients: the impact of diabetes. J Diabetes Sci Technol. 2009;3:1292-301.

27. Krinsley JS, Egi M, Kiss A, Devendra AN, Schuetz P, Maurer PM, et al. Diabetic status and the relation of the three domains of glycemic control tomortality in critically ill patients: an international multicenter cohort study. Crit Care. 2013;17:R37. 
28. Rady MY, Johnson DJ, Patel BM, Larson JS, Helmers RA. Influence of individual characteristics on outcome of glycemic control in intensive care unit patients with or without diabetes mellitus. Mayo Clin Proc. 2005;80:1558-67.

29. Krinsley JS. Glycemic control, diabetic status, and mortality in a heterogeneous population of critically ill patients before and during the era of intensive glycemic management: six and one-half years experience at a university-affiliated community hospital. Semin Thorac Cardiovasc Surg. 2006;18:317-25.

30. Pidcoke HF, Baer LA, Wu X, Wolf SE, Aden JK, Wade CE. Insulin effects on glucose tolerance, hypermetabolic response, and circadian-metabolic protein expression in a rat burn and disuse model. Am J Physiol Regul Integr Comp Physiol. 2014;307:R1-10.

31. Tsuruta R, Miyauchi K, Yamamoto T, Dohi S, Tambara K, Dohi T, et al. Effect of preoperative hemoglobin Alc levels on long-term outcomes for diabetic patients after off-pump coronary artery bypass grafting. J Cardiol. 2011;57:181-6.
32. Matsuura K, Imamaki M, Ishida A, Shimura H, Niitsuma Y, Miyazaki M. Off pump coronary artery bypass grafting for poorly controlled diabetic patients Ann Thorac Cardiovasc Surg. 2009;15:18-22.

33. Kinoshita T, Asai T, Suzuki T, Kambara A, Matsubayashi K. Preoperative hemoglobin A1c predicts atrial fibrillation after off-pump coronary bypass surgery Eur J Cardiothorac Surg. 2012;41:102-7.

34. Casqueiro J, Casqueiro J, Alves C. Infections in patients with diabetes mellitus: a review of pathogenesis. Indian J Endocrinol Metab. 2012;16:S27-36.

35. Peng J, Li X, Zhang D, Chen J-K, Su Y, Smith SB, et al. Hyperglycemia, p53, and mitochondrial pathway of apoptosis are involved in the susceptibility of diabetic models to ischemic acute kidney injury. Kidney Int. 2015;87:137-50.

Key Words: off-pump coronary artery bypass surgery, hemoglobin A1c, glycemic variability, morbidity, mortality, diabetes 